Article

\title{
Coupling of Immobilized Photosynthetic Bacteria with a Graphene Oxides/PSF Composite Membrane for Textile Wastewater Treatment: Biodegradation Performance and Membrane Anti-Fouling Behavior
}

\author{
Jing Cheng ${ }^{1}$, Xiaofeng $\mathrm{Wu}^{2}$, Binbin Jin ${ }^{1,3, *}$, Chenchen Zhang ${ }^{1,3}$, Rongwei Zheng ${ }^{1}$ and Lei Qin ${ }^{4, *(D)}$ \\ 1 Department of Hydraulic Engineering, Zhejiang Tongji Vocational College of Science and Technology, \\ Hangzhou 311231, China; feijing1987@126.com (J.C.); zhangcc1988@foxmail.com (C.Z.); \\ zjzrw0910@126.com (R.Z.) \\ 2 Yiwu Academy of Science and Technology, Zhejiang University of Technology, Jinhua 322000, China; \\ zjutywyjy@163.com \\ 3 College of Water Conservancy and Hydropower Engineering, HoHai University, Nanjing 210098, China \\ 4 Institute of Oceanic and Environmental Chemical Engineering, Zhejiang University of Technology, \\ Hangzhou 310014, China \\ * Correspondence: kinbinbin@163.com (B.J.); qinlei0214@zjut.edu.cn (L.Q.); Tel.: +86-0571-8832-0470 (L.Q.)
}

Citation: Cheng, J.; Wu, X.; Jin, B.; Zhang, C.; Zheng, R.; Qin, L.

Coupling of Immobilized

Photosynthetic Bacteria with a Graphene Oxides/PSF Composite Membrane for Textile Wastewater Treatment: Biodegradation Performance and Membrane Anti-Fouling Behavior. Membranes 2021, 11, 226. https://doi.org/ $10.3390 /$ membranes 11030226

Academic Editors: Ángel Robles Martínez, Joaquim Comas and Giorgio Mannina

Received: 26 February 2021

Accepted: 17 March 2021

Published: 22 March 2021

Publisher's Note: MDPI stays neutral with regard to jurisdictional claims in published maps and institutional affiliations.

Copyright: (c) 2021 by the authors. Licensee MDPI, Basel, Switzerland. This article is an open access article distributed under the terms and conditions of the Creative Commons Attribution (CC BY) license (https:// creativecommons.org/licenses/by/ $4.0 /)$.

\begin{abstract}
The membrane bioreactor (MBR), as one of the promising technologies, has been widely applied for treatments of wastewater. However, serious membrane fouling and low microbial activity have been reported as major problems hindering the development of the MBR. To overcome these drawbacks, we intend to improve the MBR process in the view of membrane surface modification and efficient granular bacteria cultivation. In the present study, immobilized photosynthetic bacteria integration with graphene oxide (GO)/polysulfone (PSF) composite membrane separation (IPMBR) was first applied for textile wastewater treatment. Due to the high activity of immobilized cells, the IPMBR system exhibited higher efficiency on the removal of color, ammonia-nitrogen, and chemical oxygen demand than the conventional MBR system. In comparison with a pure PSF membrane, $\mathrm{GO} / \mathrm{PSF}$ composite membrane presented the higher hydrophilicity (water contact angles of $62.9^{\circ}$ ) and more attractive permeability $\left(178.5 \mathrm{~L} / \mathrm{m}^{2} \mathrm{~h}\right)$ by reducing the adhesion of hydrophobic foulants. During the whole operation, the immobilized photobioreactor exhibited approximately seven times higher membrane permeability that that of the conventional MBR. Meanwhile, the effect of the structure and character of immobilized photosynthetic bacteria on the membrane fouling reduction was investigated in detail. The change of extracellular polymeric substance concentration, settleability and particle size of flocs was very beneficial to alleviate membrane fouling. As a result, this research will open a new avenue for developing efficient and anti-fouling MBR technology in the future.
\end{abstract}

Keywords: membrane modification; GO nanosheets; immobilized cells; membrane fouling; wastewater treatment

\section{Introduction}

Along with rapid growth of social economy and the blooming process of industrialization, textile printing and dyeing wastewater generated in China has reached one million tons every year, which often pollutes groundwater and poses a more significant risk to human health $[1,2]$. However, treatment of dye wastewater is a very difficult task, since it still has properties of high color, heavy poisonousness and is non-biodegradable even in a very low concentration [3,4]. Therefore, there is an urgent need to develop new technologies for textile wastewater advanced treatments.

In recent years, diverse treatments processes, for example, coagulation, advanced chemical oxidation, adsorption, and biodegradation treatment, have been applied to solve 
the dye wastewater problem $[5,6]$. However, high cost, low efficiency, secondary pollution, and extra additive requirements are some troubling disadvantages to these methods. To overcome those disadvantages and problems, there is an efficient option, biological treatment, the most used method in practice over the world because of its simplicity and low cost $[7,8]$. Compared with traditional biological methods (including activated sludge and the sequencing batch reactor), the submerged membrane bioreactor (SMBR) has great potential as a most promising biological treatment technology [9-12]. Nevertheless, the previous research has demonstrated that the conventional aerobic MBR is not considered a saving and feasible alternative owing to the low biodegradability of reactive soluble dyes [13,14]. Moreover, membrane fouling due to the poor settling properties and small size of the microbe cell are always considered as main problems limiting the wide application of the SMBR [15]. Over past decades, lots of strategies have been developed to alleviate membrane fouling including the membrane surface modification, operating conditions optimization, and design of the combined systems [16-18]. However, it is worth noting that the structure and characteristics of flocs in the bioreactor are important for membrane fouling reduction. Therefore, the development of efficient MBR technology will become the key to solving environmental pollution problems.

In order to address these difficulties, previous studies have paid more attention for screening and cultivating highly efficient strains rather than the activated sludge for treating refractory organic wastewater [19]. Results showed that using photosynthetic bacteria (PSB) is a promising strategy for improving the bio-treatment of reactive dye in the biological process [20]. Meanwhile, the cultivated PSB cells are always applied for high-value nutrition, animal feed and agrochemical applications [21,22]. However, suspended PSB is easily influenced by the hydraulic condition, which is susceptible to other living creatures. Moreover, reducing membrane biofouling remains a significant challenge while operating under high biomass conditions [23]. Therefore, the immobilizing PSB within the carrier is very important, which can obviously improve their settling property, poison resistance, and tolerance [24]. As well known, microorganism immobilized technology has been used in field of environmental protection, biological production and pharmaceutical engineering $[25,26]$. As reported in the previous studies, the use of an immobilized carrier provides many advantages over protecting them from environmental stress/shock loading and be easily recovered, compared with suspension cultures [27]. Especially for MBR application, small-sized microorganisms entrapped within capsules were very efficient for membrane biofouling reduction [28]. In recent years, microorganisms encapsulated into spherical alginate beads have been applied in various applications owing to their high biocompatibility and simple preparation [29]. Moreover, membrane modification containing nanomaterial blending as a promising alternative has been a topic of much interest [30]. Among various nanomaterials, graphene oxide (GO) nanosheets, as a new type of two-dimensional structural material, gained more attentions in membrane modification due to their high surface area, strong hydrophilicity of oxygen-contained groups, and good compatible and mechanical properties [31]. As reported by previous studies, a polyvinylidene fluoride (PVDF) membrane blended with $\mathrm{GO}$ or $\mathrm{GO} / \mathrm{Cu}_{\mathrm{x}} \mathrm{O}$ nanoparticles was successfully used for wastewater treatment, which exhibited higher hydrophilicity and permeability, lower cleaning frequency, and producing longer filtration time than the pristine membrane [32,33]. Thus far, the fabrication of an antifouling membrane by blending GO nanosheets into the polymer host has been often performed; however, there have been no reports on development of an advanced membrane bioreactor (MBR) system coupled with the immobilized microbes with a modified membrane.

Based on the previous observations and our research, we intend to develop a novel immobilized PSB integrated with GO/polysulfone (PSF) composite membrane for methylene blue wastewater treatment, in which gathering of highly active PSB on chemical oxygen demand (COD) and $\mathrm{NH}_{3}-\mathrm{N}$ removal can be easily performed on a large scale and membrane biofouling can be effectively mitigated by the incorporation of GO nanosheets and granular bacteria. The morphology and surface properties of the prepared GO/PSF 
composite membrane were characterized. To compare with the original PSF membrane, the antifouling behavior of the GO/PSF composite membrane was evaluated in the immobilized photobioreactor. For comparison, an MBR with immobilized photosynthetic bacteria and a controlled MBR with suspend cells were operated in parallel for 30 days. In this work, we mainly evaluate the performance of an immobilized photosynthetic bacteria MBR (IPMBR) in terms of biomass concentration, organic contaminants removal efficiency, and membrane permeability. Moreover, the variations on the properties and microscopic structure of flocs in two MBRs, such as settleability, particle size and extracellular polymeric substance concentration (EPS) were also analyzed for a better understanding of the anti-fouling behavior.

\section{Materials and Methods}

\subsection{Chemicals and Materials}

The commercial methylene blue is available from Beta pharma Co., Ltd. (Shanghai, China). Sodium alginate (SA), polyethylene glycol, calcium chloride $\left(\mathrm{CaCl}_{2}\right)$, sodium chloride $(\mathrm{NaCl})$ and sodium hydroxide $(\mathrm{NaOH})$ were bought from Sinopharm chemical Reagent Co. Ltd. (Hangzhou, China). The components of textile wastewater are shown in Table 1, showing a high organic pollutant loading (max COD of $1025 \mathrm{mg} / \mathrm{L}$ ) and ammonia nitrogen $\left(\max \mathrm{NH}_{3}-\mathrm{N}\right.$ of $112 \mathrm{mg} / \mathrm{L}$ ). Moreover, the $\mathrm{pH}$ of wastewater was varied between 6.0 and 8.0. Photosynthetic bacteria (PSB) were selected from purified and identified Rhodopuesdomonas pulstris, which were cultured and grown in RCVBN medium $\left(0.1 \mathrm{~g} / \mathrm{L} \mathrm{NH}{ }_{4} \mathrm{Cl}, 0.5 \mathrm{~g} / \mathrm{L} \mathrm{NaCl}, 0.5 \mathrm{~g} / \mathrm{L} \mathrm{NaHCO}_{3}, 3.0 \mathrm{~g} / \mathrm{L} \mathrm{CH}_{3} \mathrm{COONa}_{3} \mathrm{H}_{2} \mathrm{O}, 0.1 \mathrm{~g} / \mathrm{L}\right.$ $\mathrm{MgSO}_{4} \cdot 7 \mathrm{H}_{2} \mathrm{O}, 0.1 \mathrm{~g} / \mathrm{L} \mathrm{CaCl}_{2} \cdot 2 \mathrm{H}_{2} \mathrm{O}, 0.2 \mathrm{~g} / \mathrm{L} \mathrm{K} \mathrm{HPO}_{4}, 0.5 \mathrm{~g} / \mathrm{L}$ yeast extract, and $0.5 \mathrm{~g} / \mathrm{L}$ peptone) under shaking. Throughout the whole cultivation, the irradiate intensity, solution $\mathrm{pH}$ and temperature were altered to approximately $3000 \mathrm{lux}, 7.5$ and $25^{\circ} \mathrm{C}$, respectively.

Table 1. Synthetic textile wastewater characterization.

\begin{tabular}{cc}
\hline Composition & Concentration $(\mathrm{mg} / \mathrm{L})$ \\
\hline Glucose & 350 \\
Sodium acetate anhydrous & 200 \\
$\mathrm{NH}_{4} \mathrm{Cl}$ & 300 \\
$\mathrm{KH}_{2} \mathrm{PO}_{4}$ & 25 \\
$\mathrm{KNO}_{3}$ & 50 \\
$\mathrm{CaCl}_{2} \cdot 2 \mathrm{H}_{2} \mathrm{O}$ & 8 \\
$\mathrm{MgCl}_{2} \cdot 6 \mathrm{H}_{2} \mathrm{O}$ & 12 \\
$\mathrm{Methylene} \mathrm{blue}(\mathrm{MB})$ & 20 \\
$\mathrm{COD}^{1}(\mathrm{mg} / \mathrm{L})$ & $660-1025$ \\
$\mathrm{NH}_{3}-\mathrm{N}(\mathrm{mg} / \mathrm{L})$ & $83-112$ \\
$\mathrm{pH}$ & $6.0-8.0$ \\
$\mathrm{SS}^{2}(\mathrm{mg} / \mathrm{L})$ & $200-300$ \\
\hline
\end{tabular}

${ }^{1}$ chemical oxygen demand; ${ }^{2}$ suspended solids.

\subsection{Preparation of GO/PSF Composite Membrane}

The GO/PSF composite membrane was prepared through the phase inversion method. Firstly, Graphene oxide (GO) nanosheets were prepared from the Nanjing Xianfeng Nanomaterials Co., Ltd. (Nanjing, China) by means of the modified Hummers method [34]. Secondly, the as-synthesized GO nanosheets (1 wt \%) and post-treated polysulfone (18 wt \%) were dissolved in dimethylacetamide (DMAc). Then, the mixture solution was cast onto a clean glass plate, evaporated in air and placed in deionized water coagulation bath.

\subsection{Immobilizing of Photosynthetic Bacteria into Hydrogel}

In this work, PSB cells were encapsulated into hydrogel by way of the embedding method. The pathway used to fabricate sodium alginate (SA) entrapped beads was similar to the previously reported pathways [35]. The embedding agent solution was consisted 
of the polyethylene glycol and sodium alginate. The cultivated photosynthetic bacteria were immersed into the embedding agent for $20 \mathrm{~h}$. Depending on the saturated boric acid solution (cross-linking agent), the hydrogel macrospheres with 2-4 mm diameter was prepared with large numbers of PSB cells. Subsequently, immobilized sphere was immersed in $2 \% \mathrm{CaCl}_{2}$ solution further fixed in the fridge, and which was then washed with sterile water and stored in $0.85 \% \mathrm{NaCl}$ solution.

\subsection{Characterizations}

The structure and morphology of modified membranes were characterized by JEM1200EX scanning electron microscopy (SEM, Hitachi, Tokyo, Japan). The water contact angle (CA) of the GO/PSF composite membrane was measured by using the sessile drop method (OCA50AF, Dataphysics, Filderstadt, Germany). The surface functional groups of GO nanosheets were analyzed through Fourier Transform Infrared spectroscopy (FTIR, iS50, Thermo Fisher Nicolet, Waltham, USA). X-ray diffraction (XRD, X'Pert PRO, PNAlytical, Holland) was used to investigate the crystal structure of nanosheets. Scanning electron microscopy (SEM) images of outside surface morphology for cell-encapsulated particles were performed. Living/dead cells of encapsulated hydrogel spheres were visually monitored by the inverted fluorescence microscope.

\subsection{Experimental Setup}

The laboratory equipment used in this study is shown in Figure 1. To analyze the influence of membrane modification and cell immobilization on dye degradation and membrane fouling, two SMBRs of the same size were run in parallel under the same conditions with a working volume of $10 \mathrm{~L}$, one an immobilized photosynthetic bacteria MBR (IPMBR) and another a controlled MBR (CMBR). A level sensor connected with a feeding pump was used for constant volume control. The self-made flat sheet GO/PSF composite membrane module with the effective membrane area of $0.05 \mathrm{~m}^{2}$ was immersed into the bioreactor. Air $\left(1.5 \mathrm{~m}^{3} / \mathrm{m}^{2} \mathrm{~h}\right)$ was continuously poured into every reactor at the same flow rate. The effluent was supplied back to the bioreactor continuously, while the SMBR system was operated in constant flow mode with $10 \mathrm{~min}$ inhalation and followed by 2 min relaxation. The transmembrane pressure (TMP) was continually monitored as a signal to indicate the membrane fouling. The hydraulic residence time (HRT) and solid residence time (SRT) were set at $40 \mathrm{~h}$ and $30 \mathrm{~d}$, respectively.

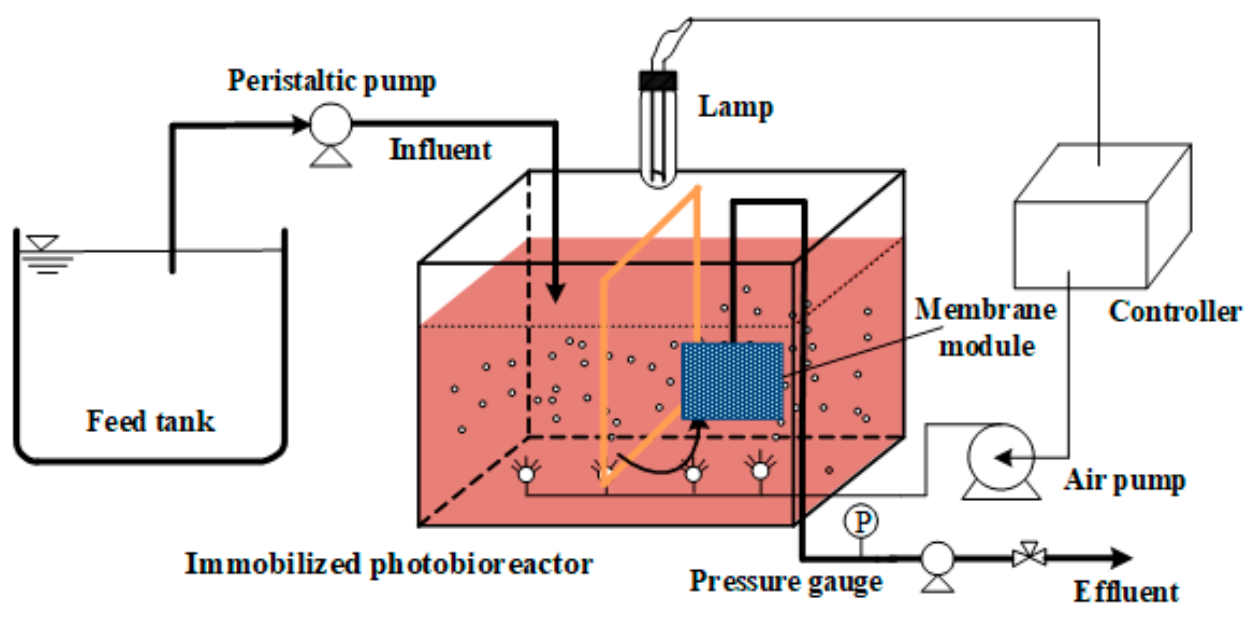

Figure 1. Schematic diagram of the experimental process.

\subsection{Measurement of PSB Biomass Concentration}

The concentration of PSB cells was measured by using the spectrophotometry method at the wavelength of $805 \mathrm{~nm}$, being calculated as follows (Equation (1)):

$$
\operatorname{Biomass}(g / L)=1.3677 \times O D_{805}-2.7 \times 12^{-2}\left(R^{2}=0.9987\right)
$$


where $O D_{805}$ is optical density of the free PSB solution; Biomass presents the dry weight of microbes.

The PSB biomass of hydrogel was determined through the weight difference method. A certain number of hydrogels were placed in an oven at $80^{\circ} \mathrm{C}$ for $6 \mathrm{~h}$ to dry, and the weight of which was marked as $m_{1}$. Additionally, the hydrogel was then heated at high temperature to volatilize bacteria, and the weight of which was marked as $m_{2}$. The difference value of $m_{1}$ and $m_{2}$ is the weight of PSB encapsulated in hydrogel.

\subsection{Calculation of Membrane Permeability and Filtration Resistance}

Membrane fouling of the different integrated systems was evaluated through the variation of membrane flux over time. The membrane permeability was calculated by Equation (2) as follows:

$$
L_{p}\left(\mathrm{~L} / \mathrm{m}^{2} \cdot \text { bar }\right)=\frac{J_{p}}{\Delta p_{T M}}
$$

where $J_{p}$ is the permeate flux $\left(\mathrm{L} / \mathrm{m}^{2} \mathrm{~h}\right), \Delta p_{T M}$ represents the transmembrane pressure (bar).

The fouled membrane was cleaned after 15 days by physical and chemical methods. The total filtration resistance $\left(R_{t}, \mathrm{~m}^{-1}\right)$ is determined by Darcy's law (Equation (3)):

$$
R_{t}=R_{m}+R_{f}=\frac{\Delta p_{T M}}{\mu \cdot J_{p}}
$$

where $R_{t}, R_{m}$ and $R_{f}$ present the total membrane filtration resistance $\left(\mathrm{m}^{-1}\right)$, the original membrane filtration resistance $\left(\mathrm{m}^{-1}\right)$ and the filtration resistance after fouling $\left(\mathrm{m}^{-1}\right)$, respectively. $\mu$ represents the permeate viscosity $\left(\mathrm{Pa}^{-1} \cdot \mathrm{s}\right)$. To evaluate membrane fouling, the surfaces of membranes before and after filtration were also examined by SEM.

\subsection{Analytical Methods}

To measure and estimate the ammonia-nitrogen $\left(\mathrm{NH}_{3}-\mathrm{N}\right)$, $\mathrm{COD}$, mixed liquor volatile suspended solids (MLVSS) and sludge volume index (SVI), standard analytical methods were carried out [36]. The concentration of methylene blue (MB) was determined by a U-2910 digital spectrophotometer (Hitachi, Japan). The size distribution of the flocs in the MBR was determined by a Malvern Mastersizer 2000 (Malvern, Worcestershire, UK). Heat treatment was used to extract the EPS from free microbes and cells-encapsulated flocs, and the total of the EPS was calculated and regarded as total organic carbon (TOC) contents based on the sample supernatant.

\section{Results and Discussion}

\subsection{Characterization of GO Modified Composite Membrane}

The surface structure of the prepared GO/PSF composite membranes was characterized by SEM images and is shown in Figure $2 a$ and $b$. As apparent from the figure, it was found that the modified GO/PSF membrane presented the rough surface owing to the exposure of blended GO nanosheets. The cross-sectional image displays that the prepared ultrafiltration membranes present a typical construction with an asymmetric finger-like porous sub-layer and a dense skin layer. By comparison, the phase inversion rate after altered after the introduction of hydrophilic GO nanocomposites, making the pores of the membrane larger so that water molecules can pass through the membrane easier. In the XRD pattern, the characteristic peak at $2 \theta=10.3^{\circ}$ belongs to GO nanosheets (Figure 2e). Figure $2 \mathrm{f}$ presents the FTIR spectra of prepared GO nanosheets. As apparent from the figure, the typical peak at $1632 \mathrm{~cm}^{-1}$ which appeared was assigned to $\mathrm{C}=\mathrm{O}$ stretching vibrations of the GO nanosheet. Moreover, the band at $1052 \mathrm{~cm}^{-1}(=\mathrm{C}-\mathrm{O}-\mathrm{C})$ and the stretching vibration band at $1212 \mathrm{~cm}^{-1}(-\mathrm{C}-\mathrm{O})$ were obviously shown in the curve of the GO nanosheets [37]. 


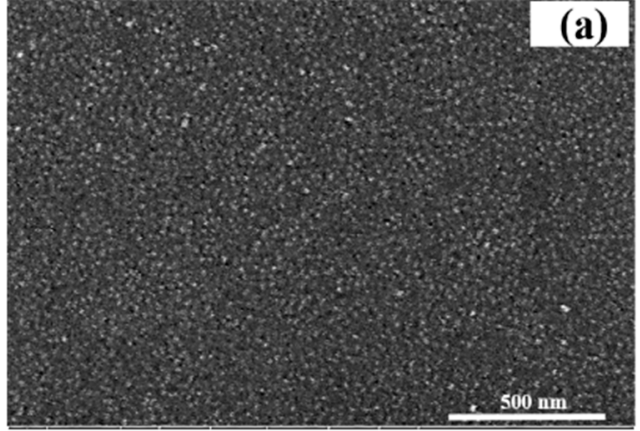

(c)
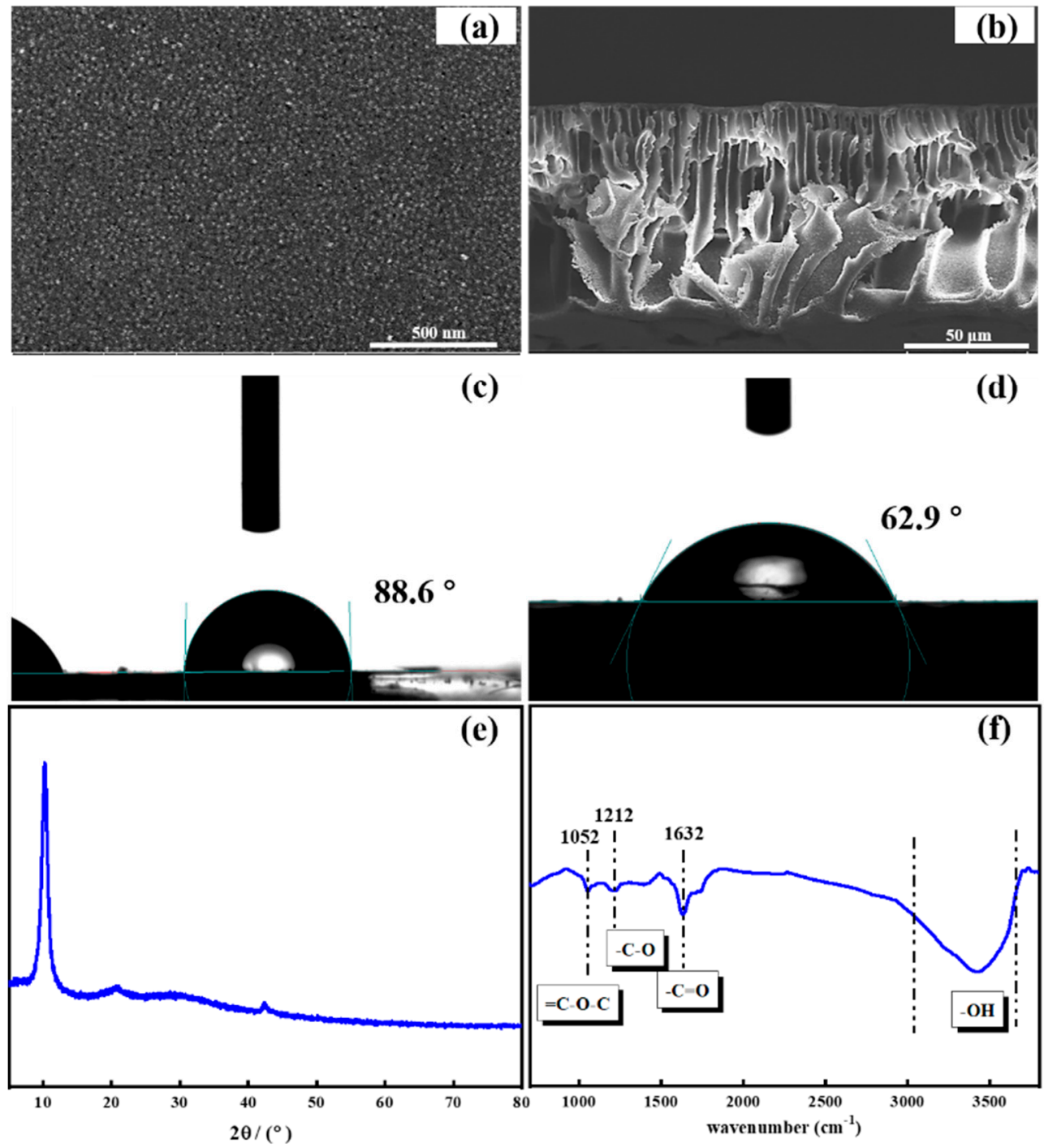

(e)

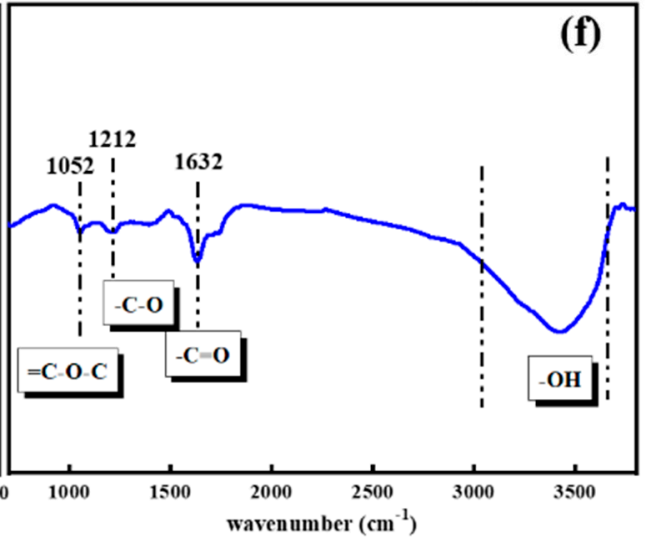

Figure 2. (a,b) Scanning electron microscopy (SEM) images of prepared graphene oxide (GO)polysulfone (PSF) composite membrane; $(\mathbf{c}, \mathbf{d})$ water contact angle of original PSF and GO-PSF composite membrane; and (e,f) X-ray diffraction (XRD) and Fourier transform infrared spectroscopy (FTIR) of the prepared GO nanosheets.

\subsection{Hydrophilicity and Filtration Performance of GO Modified Membrane}

The water contact angle was measured to investigate the surface hydrophilicity of original PSF and GO/PSF composite membrane. As illustrated in Figure 2c,d, the water contact angle of GO/PSF composite membrane reduced from 88.6 to $62.9^{\circ}$. It indicated that the surface hydrophilicity of membrane was improved by the incorporation of GO nanosheets, and thus significantly enhanced the membrane permeability. The details in the pure water flux and bovine serum albumin (BSA) rejection of the PSF membrane before and after GO modification was investigated. It was found that the pure water permeability of original PSF membrane was $63.3 \mathrm{~L} / \mathrm{m}^{2} \cdot \mathrm{h}$. After GO blending, the increase in the water flux to $178.5 \mathrm{~L} / \mathrm{m}^{2} \cdot \mathrm{h}$ was observed for the modified membrane, which is approximately 2.82 times higher than that of pure PSF membrane. Similarly with the reported GO modified membranes, the prepared composite membrane also exhibited excellent flux, which demonstrated that introducing hydrophilic GO nanosheets into the membrane matrix can the increase water transport rate [37,38]. In comparison with the PSF membrane $(90.5 \%)$, the GO-blended composite membrane possessed the higher rejection $(95.1 \%)$. The enhanced rejection of the modified membrane improved the concentration of microbes for wastewater treatment. 


\subsection{Preparation and Characterization of Immobilized Particles}

As illustrated in Figure 3, the encapsulation of PSB cells into a porous polymer hydrogel involved two procedures: (1) fast self-assembly of the polymeric hydrogel containing PSB cells, sodium alginate (SA), and polyethylene glycol (PEG) through the coordination of $\mathrm{Ca}^{2+}$; (2) strong cross-linking between the hydrogel and glutaraldehyde. The high biocompatibility and large cavity of the polymeric hydrogel provides a favorable atmosphere for PSB cells growth. Meanwhile, the cross-linked layer on the surface of macrocapsule effectively reduced the leakage of cells into solution. The surface morphology and microstructure of PSB-encapsulated macrocapsules was characterized by SEM. As shown in Figure $4 a, b$, the surface of encapsulated particles was rough, which may be attributed to the immobilization of some microorganisms into the interior cavity of the hydrogel. The diameter of globular macrocapsules was ranged from 4.0 to $5.0 \mathrm{~mm}$. In terms of surface color, it was found that the polymer hydrogel was transparent, which had a positive effect on the light utilization of the encapsulated microbe's cell.

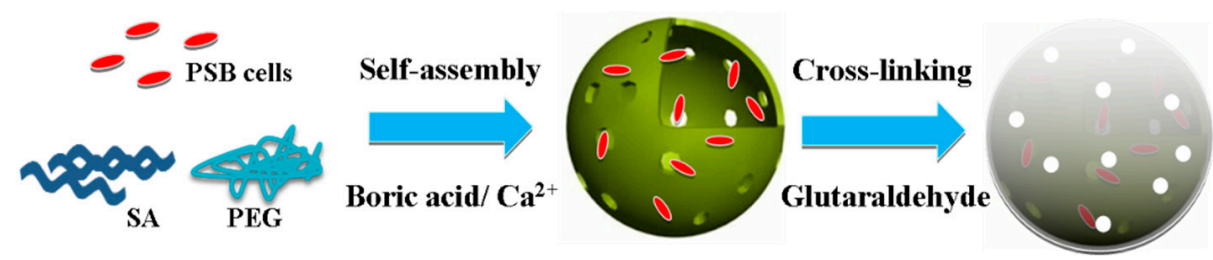

Figure 3. Schematic diagram of preparation of the photosynthetic bacteria (PSB)-encapsulated hydrogel macrosphere.
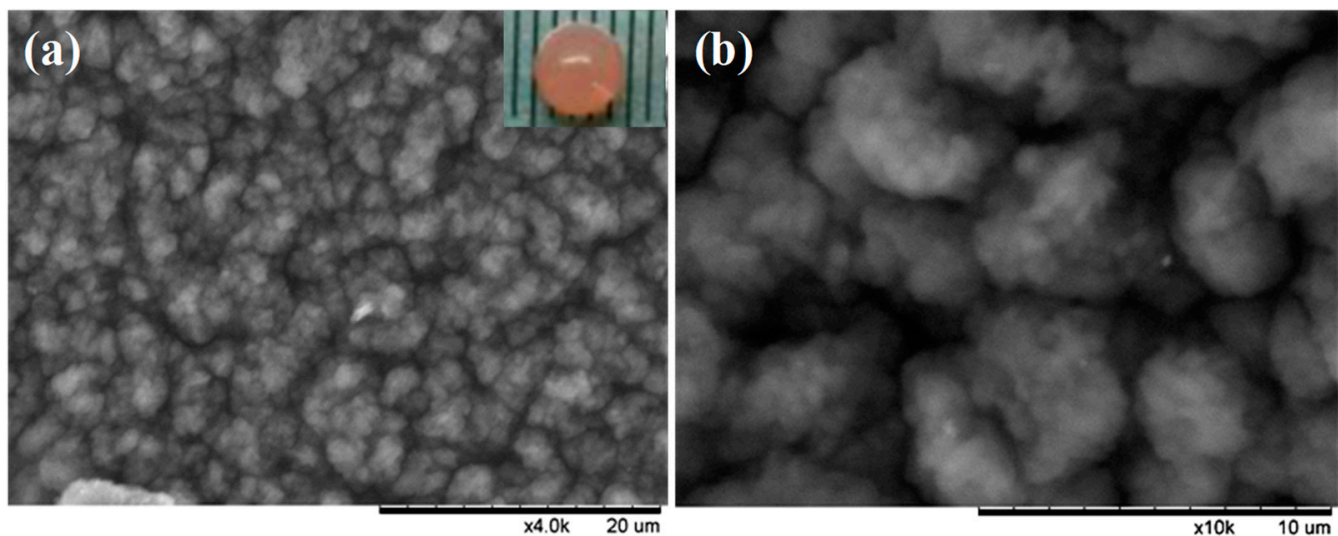

Figure 4. SEM images and photograph of the PSB-encapsulated hydrogel macrosphere.

Biomass production of free and encapsulated PSB cells with operation time increasing was monitored and measured, and the results of volumetric biomass content for two different CMBR and IPMBR systems are presented in Figure 5a. In the initial stage (3d), the free PSB concentration presented a rapid upward trend, and the biomass of the MBR system increased from 0.37 to $1.07 \mathrm{~g} / \mathrm{L}$. After 10 days, the content of biomass reached $2.49 \mathrm{~g} / \mathrm{L}$, maintaining a constant state for a long time. In comparison with the MBR, the content of encapsulated PSB cells was as high as $3.07 \mathrm{~g} / \mathrm{L}$, indicating the enhancement of PSB biomass production in the IPMBR. On average, approximately $23.3 \%$ of biomass yields for the IPMBR system were higher than the CMBR. By comparison with the previous studies, the enhanced biomass maybe due to fact that the micro-aerobic environment of the interior cavity allowed the encapsulated PSB cells to obtain more energy to improve organics' assimilation ability and maintain a high growth rate [39]. The inverted fluorescence microscope photograph also highlighted that many living cells were observed inside the cavity of the porous polymer hydrogel, while only a few dead cells (red) were shown (Figure $5 \mathrm{~b})$. However, it was found that the leakage of cells $(2.65 \mathrm{~g} / \mathrm{L})$ occurred during 
the operation. Therefore, the structural stability and mechanical strength of the polymeric macrospheres should be further strengthened in future study.

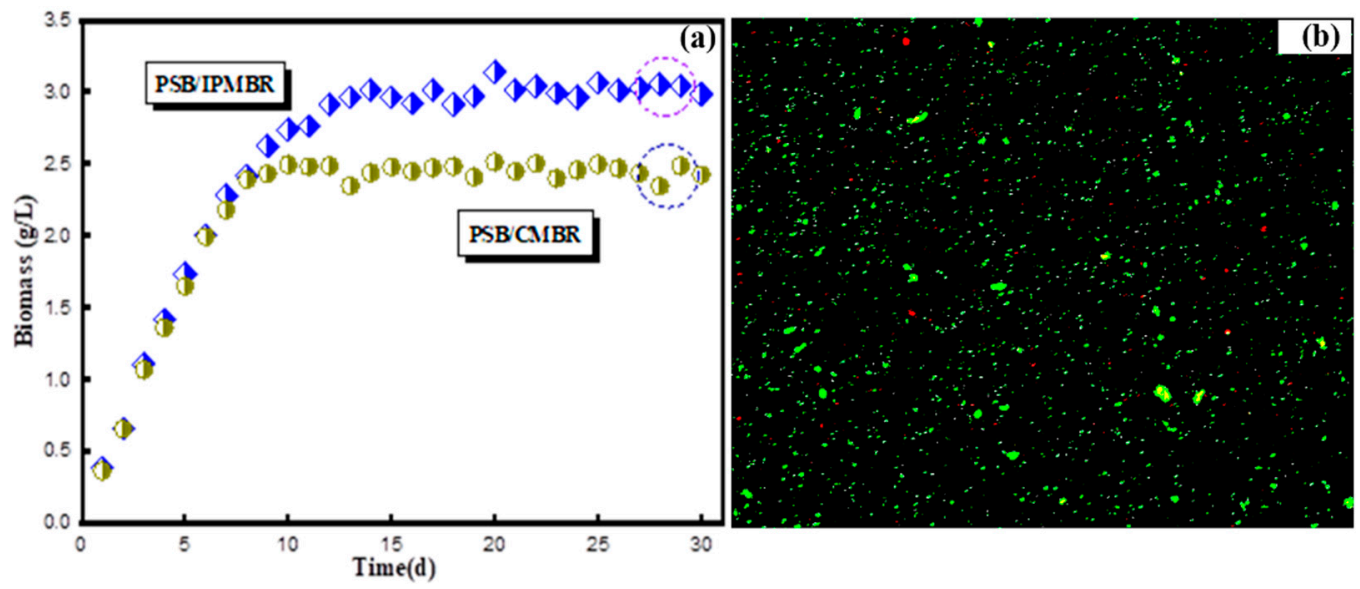

Figure 5. (a) Biomass productivity of the suspended and encapsulated system with operation time increasing. (b) Inverted fluorescence microscope photograph of the PSB-encapsulated hydrogel macrosphere.

\subsection{Performance of the Integrated System}

The true color, $\mathrm{NH}_{3}-\mathrm{N}$ of influent and effluent, the average COD and removal efficiency corresponding to the overall continuous process are presented in Table 2. As illustrated in Figure $6 a$, it was found that, during the entire operation period, the COD of textile influent floated between 1025 and $662 \mathrm{mg} / \mathrm{L}$. In the initial stage, the effluent COD fluctuated between 240 and $225 \mathrm{mg} / \mathrm{L}$. A total of 6 days later, the organic contaminants' removal efficiencies of the photo-bioreactor were enhanced steadily and afterwards maintained the removal rate up to $82.0 \%$ after bacterial adaptation in the PSB-CMBR system. In a sharp comparison, the COD concentration decreasing drastically from $150 \mathrm{mg} / \mathrm{L}$ to lower than $40 \mathrm{mg} / \mathrm{L}$ was observed in the IPMBR system, which maintained an average removal rate up to $92.6 \%$, much higher than that in the CMBR system. The tendency of COD removal performance was analogous to that of biomass production. It was suggested that the encapsulation strategy could improve the organic pollutants' degradation of microbes in the MBR. Figure $6 \mathrm{~b}$ shows the ammonia nitrogen concentration and its related removal rate in the the IPMBR and CMBR. As mentioned before, the removal rate of $\mathrm{NH}_{3}-\mathrm{N}$ in the CMBR was quite low at the start of operation, and the average rate was around $55.4 \%$. After several days, an apparent reduction in the content of $\mathrm{NH}_{3}-\mathrm{N}$ for the CMBR effluent from 45.7 to $23.8 \mathrm{mg} / \mathrm{L}$ was observed, presenting ammonia nitrogen removal with an average efficiency of $75.7 \%$. As shown in the figure, the $\mathrm{NH}_{3}-\mathrm{N}$ removal efficiency was greatly enhanced in the IPMBR with efficiency of $90.7 \%$, which is in accordance with the trend of organic pollutants' removal performance. At the same time, a similar trend was also found for the color removal, the efficiency of which for the IPMBR $(92.3 \%)$ was much higher than that for the CMBR (74.8\%). Compared with the CMBR, the higher biodegradation performance of the IPMBR was mainly attributed to the fact that the immobilization strategy created the confined environment for PSB harvesting and protected living cells away from physical/chemical stress $[40,41]$. This reveals well that immobilizing of photosynthetic bacteria played positive roles on the dye wastewater treatment. 
Table 2. COD, true color, and $\mathrm{NH}_{3}-\mathrm{N}$ in the integrated process (average values in concentration).

\begin{tabular}{ccccccc}
\hline \multirow{2}{*}{ Process Unit } & \multicolumn{2}{c}{ COD } & \multicolumn{2}{c}{ True Color } & \multicolumn{2}{c}{$\mathbf{N H}_{\mathbf{3}}-\mathbf{N}$} \\
\cline { 2 - 7 } & Con. (mg/L) & Rem. (\%) & Abs & Rem. (\%) & Con. (mg/L) & Rem. (\%) \\
\hline Raw & 845.6 & 0 & 0.571 & 0 & 98.4 & 0 \\
IPMBR ${ }^{1}$-supernatant & 134.7 & 84.1 & 0.083 & 85.5 & 24.1 & 75.5 \\
IPMBR effluent & 62.9 & 92.6 & 0.044 & 92.3 & 15.8 & 84.0 \\
CMBR $^{2}$-supernatant & 239.0 & 71.7 & 0.178 & 68.8 & 31.3 & 68.2 \\
CMBR effluent & 162.1 & 80.8 & 0.144 & 74.8 & 23.8 & 75.7 \\
\hline
\end{tabular}

${ }^{1}$ immobilized photosynthetic bacteria MBR; ${ }^{2}$ controlled MBR.
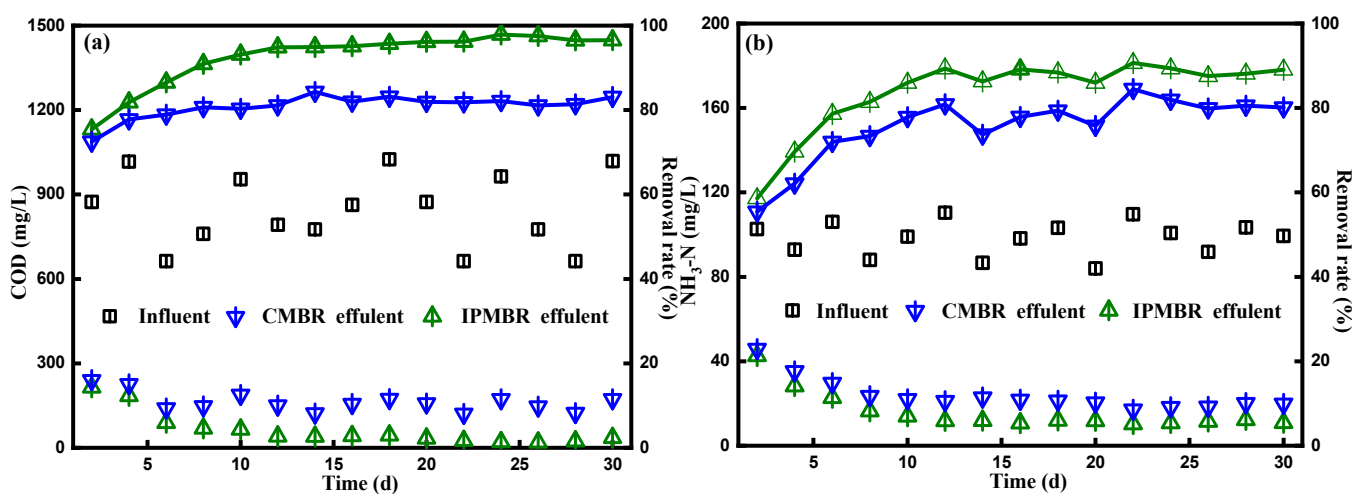

Figure 6. (a) Variation of the concentration of chemical oxygen demand (COD) and corresponding removal efficiency and (b) variation of the content and removal efficiency of $\mathrm{NH}_{3}-\mathrm{N}$ in different PSB-membrane bioreactors (MBRs) systems.

\subsection{Comparison of Membrane Permeability on Different Integrated Systems}

Membrane permeability in the CMBR and IPMBR systems with the time variation during the operation periods is shown in Figure 7a. Evidently, the initial permeability of the two reactors decreased rapidly. In the CMBR, the permeability of the membrane decreased from initial 168.1 to $69.6 \mathrm{~L} / \mathrm{m}^{2} \cdot \mathrm{h} \cdot$ bar during $24 \mathrm{~h}$ operation. However, the membrane flux was constant about $3.7 \mathrm{~L} / \mathrm{m}^{2} \cdot \mathrm{h} \cdot$ bar after 9 days. In the IPMBR, the membrane permeability was $169.3 \mathrm{~L} / \mathrm{m}^{2} \cdot \mathrm{h} \cdot \mathrm{bar}$, well above the CMBR in the corresponding period, and the steadystate permeability was $24.1 \mathrm{~L} / \mathrm{m}^{2} \cdot \mathrm{h} \cdot \mathrm{bar}$. It demonstrated that the addition of immobilized photosynthetic bacteria significantly inhibits the membrane fouling.
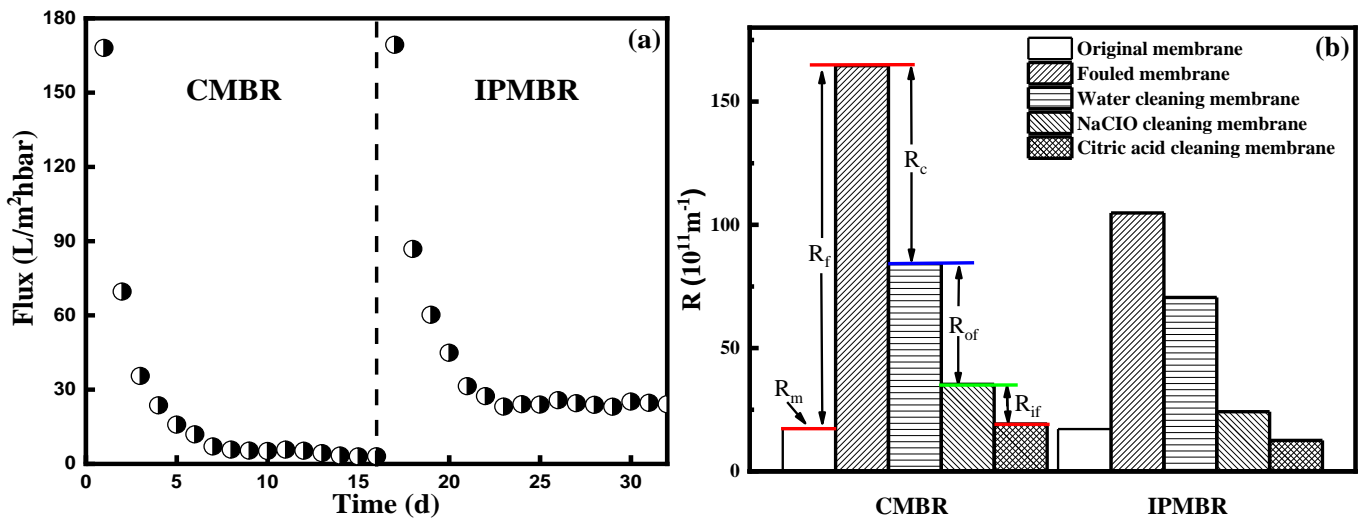

Figure 7. (a) Time-variation of permeability on the membrane during the controlled MBR (CMBR) and immobilized photosynthetic bacteria MBR (IPMBR) operation and (b) filtration resistances calculated during the filtration with different PSB-MBRs.

To further explore the main reasons of fouling behavior in two integrated systems, the membrane filtration resistances were calculated (Figure $7 \mathrm{~b}$ ). By comparison, obviously 
the membrane resistance $\left(R_{m}\right)$ was the minority of overall resistance $(10.5 \%$ and $16.4 \%$ for the two MBR systems), but higher resistance due to the formation of a cake layer was observed during filtering [42,43]. In comparison with the CMBR $(48.8 \%)$, it was found that the significant reduction in filtration resistance $\left(\mathrm{Rc}_{\mathrm{c}}, 32.7 \%\right)$ in the cake layer was shown in the IPMBR system. Meanwhile, SEM images of fouled membranes were characterized to analyze the deposition of flocs on the surface (Figure 8). After operation in the CMBR later, nearly all the surfaces of the membrane were fully covered by cake layer densely. However, evidently the deposition of fewer particles on the membrane surface during the IPMBR process was observed compared with the CMBR. The observation illustrated well that the cell encapsulation strategy played vital roles in protecting the deposition of cake layer on the membrane surface. Moreover, it was demonstrated that large numbers of PSB cells were immobilized into porous macrospheres, which could be beneficial to enhancing the performance of the MBR in treating wastewater. It was noted that the filtration capacity of the membrane was closely related to the characteristics of sludge flocs in the bioreactor $[44,45]$. Therefore, in order to understand what influences immobilized photosynthetic bacteria in terms of membrane fouling, the various characteristics of the immobilized microorganism were investigated in detail.
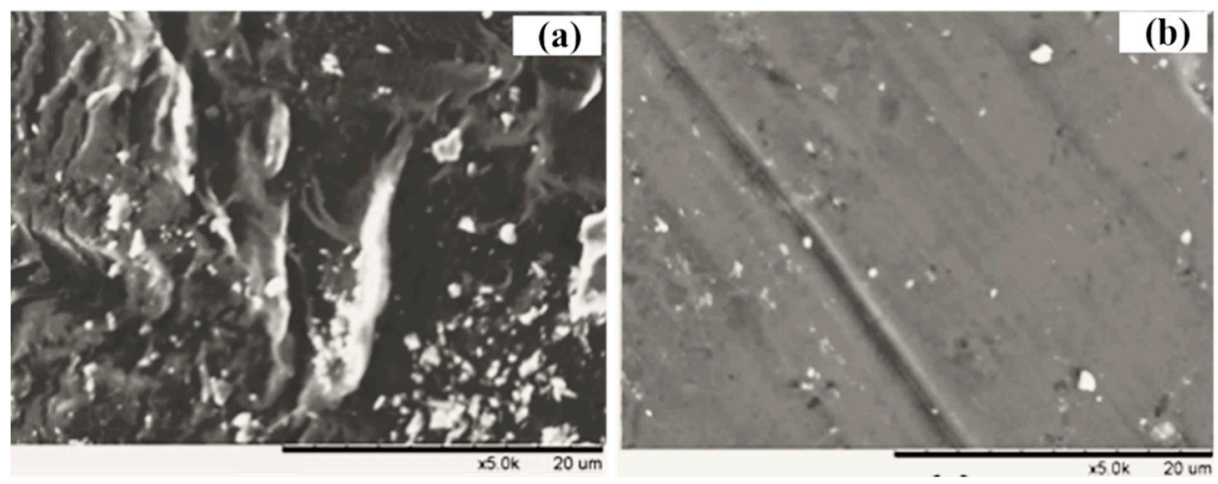

Figure 8. SEM images of fouled membrane in the CMBR (a) and in the IPMBR (b).

\subsection{Characteristics of Sludge Flocs in Integrated System}

Extracellular polymeric substance (EPS) is usually considered to be the main structural component of the sludge flocs, whose characteristics and concentration played a significant role in the membrane permeability [46]. In this study, the role of cell immobilizing on the flocs' properties was investigated based on the bound EPS (bEPS) concentration. As is shown in Figure 9, the content of bEPS in the bioreactor varied significantly with operation time in the two MBRs. For the CMBR system, the quantity of EPS increased from 39.5 to $52.4 \mathrm{mg}$-TOC/g-MLVSS in the initial 14 days. However, the concentration of EPS was stabilized, maintaining around $47.0 \mathrm{mg}$-TOC/g-MLVSS after 20 days. The concentration of bEPS in the IPMBR was lower than that in the CMBR, and the value range of which was varied from 20 to $30 \mathrm{mg}$-TOC/g-MLVSS. The obvious decrease in bound EPS concentration may be attributed to large amount of of polymeric substances adsorbed on the surface of porous supports. Moreover, the shell of the hydrogel macrospheres prevented the release of metabolic polymeric substance into mixed liquid. As previous studies reported, there was no significant linear relationship between bEPS and TMP, and the low concentration of bEPS was conductive to the decline in TMP and enhancement of membrane filtration [47]. 


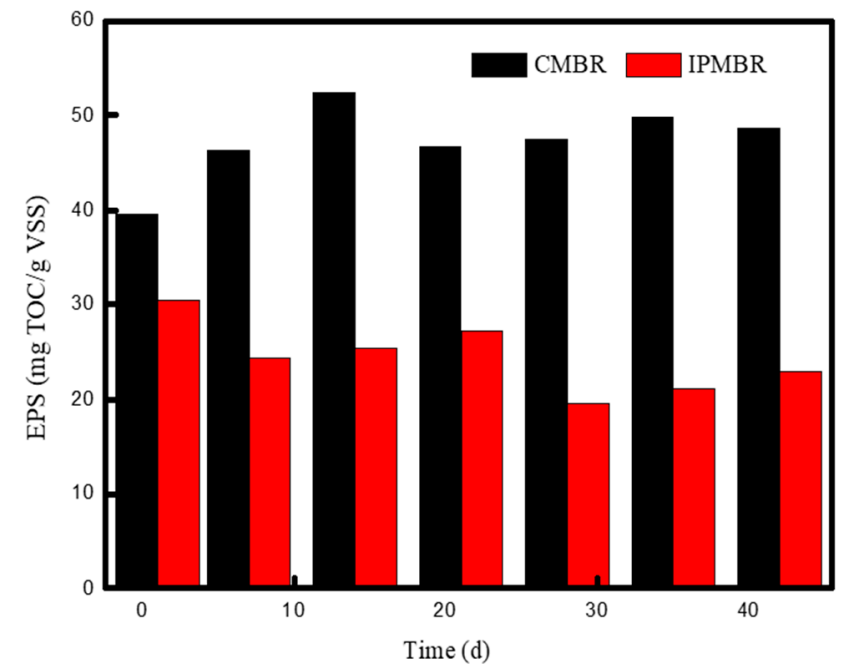

Figure 9. Variation of extracellular polymeric substance concentrations (EPS) of microorganism with operation time in different MBRs.

As is well known, the influence of flocs' size on the membrane permeability is usually explored in the MBR system [48,49]. As isapparent from the figure, it was found that large numbers of small photosynthetic bacteria were aggregated into the immobilized polymer hydrogel, and the diameter of the sphere was about $3.2 \mathrm{~mm}$, much larger than that of conventional PSB bacteria $(0.5-2 \mu \mathrm{m})$ of the CMBR system. Here is the Carman-Kozeny equation (Equation (4)), providing vital information of the specific resistance $(\alpha)$ of the cake layer relating closely to the particle size, and it is inversely proportional to square of the particle diameter:

$$
\alpha=\frac{180(1-\varepsilon)^{2}}{\rho_{p} d_{p}^{2} \varepsilon^{3}}
$$

where $\varepsilon$ is the cake porosity, $d_{p}$ is the particle size $(\mathrm{m})$, and $\rho_{p}$ presents the particle density $\left(\mathrm{kg} / \mathrm{m}^{3}\right)$. The results confirmed that the obvious increase in the particles size of small microorganism cell significantly improve the permeability of the IPMBR system.

In general, the aggregate structure of primary flocs plays a vital role in the physicochemical properties of flocs including flocculation capacity and sediment ability. SVI is often applied to estimate the settleability and compressibility of flocs. Better settleability can enhance the porosity of cake layer, thus increasing the permeability of the membrane [50]. Figure 10 presents the variations of SVI with increasing of operation time in the CMBR and IPMBR. Different traditional activated sludge, the settleability of PSB cells in the bioreactor is always poor, which was attributed to the rare presence of microbe-attached particles. It was found that the microbes of the CMBR held the poor settleability with SVI of $128.14 \mathrm{~mL} / \mathrm{g}$ in the initial stage. With increasing operation time, a slight increase in SVI to $168 \mathrm{~mL} / \mathrm{g}$ was observed for the CMBR. As reported by previous studies, the high EPS concentration had a passive impact on flocs' compressibility and settleability [51,52]. Therefore, it suggested that the weakened settleability of PSB cells in the CMBR can be due to more negatively charged substances adsorbed on surface of living cells. In sharp contrast, a quick reduction in SVI from 85.7 to $60.5 \mathrm{~mL} / \mathrm{g}$ was observed in the initial stage of operation in the IPMBR system. When operated at 18 days, the SVI was descended to $54.7 \mathrm{~mL} / \mathrm{g}$, substantially lower than that of microbes in the CMBR systems. However, when the operation time was further prolonged, the SVI of the IPMBR was obviously increased owing to the leakage of PSB cells from the polymeric hydrogel. Moreover, the photograph of the mixed liquid also evidently presented an influence of immobilizing on the settleability and morphological feature of microbes compared with the CMBR. This reveals that the compressibility and settleability were significantly improved in the IPMBR system. The 
above results well demonstrate that the encapsulation strategy played important roles in the compressibility and settleability of microbes.

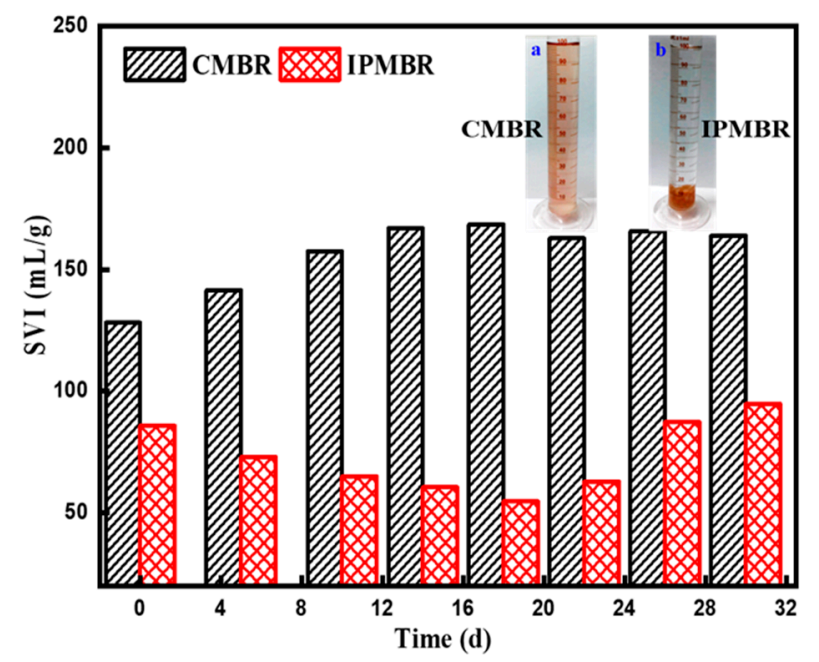

Figure 10. Variation of sludge volume index (SVI) of microorganisms with operation time in different MBRs and photographs of the microorganism in the CMBR (a) and IPMBR (b) systems.

\section{Conclusions}

In this study, a GO/PSF composite membrane was integrated with immobilized a PSB bioreactor for wastewater advanced treatment. A GO blended membrane with enhanced hydrophilicity and antifouling property was successfully applied for high-active PSB strain harvesting. The results show that the novel combined process on $\mathrm{COD}$, color, and $\mathrm{NH}_{3}-\mathrm{N}$ removal were excellent and stable with averages $>88 \%$. Owing to introduction of GO nanosheets and granular bacteria, the IPMBR process exhibited approximately seven times higher membrane permeability than the conventional MBR system. The decrease in EPS content, the improvement of compressibility and settleability, and the increase in particle size benefited membrane reduction. Therefore, this work will bring new insight for the development of efficient and anti-fouling MBR technology for various applications.

Author Contributions: Conceptualization, J.C. and L.Q.; methodology, L.Q.; formal analysis, B.J. and X.W.; writing - original draft preparation, J.C. and L.Q.; and writing—review and editing, C.Z. and R.Z. All authors have read and agreed to the published version of the manuscript.

Funding: This research was funded by National Natural Science Foundation of China (Grant No. 21506193), Zhejiang Provincial Natural Science Foundation of China (Grant No. LY18B060010), Scientific Research Foundation of Zhejiang Provincial Education Department (Y201840641), and Zhejiang Provincial Water Resources Department (Grant No. RC1725).

Institutional Review Board Statement: Not applicable.

Informed Consent Statement: Not applicable.

Data Availability Statement: Not applicable.

Acknowledgments: Financial support for this work was provided by the National Natural Science Foundation of China (Grant No. 21506193), Zhejiang Provincial Natural Science Foundation of China (Grant No. LY18B060010), Scientific Research Foundation of Zhejiang Provincial Education Department (Y201840641), and Zhejiang Provincial Water Resources Department (Grant No. RC1725).

Conflicts of Interest: The authors declare no conflict of interest. 


\section{References}

1. Lee, K.M.; Lai, C.W.; Ngai, K.S.; Juan, J.C. Recent Developments of Zinc Oxide Based Photocatalyst in Water Treatment Technology: A Review. Water Res. 2016, 88, 428-448. [CrossRef]

2. Vikrant, K.; Giri, B.S.; Raza, N.; Roy, K.; Kim, K.H.; Rai, B.N.; Singh, R.S. Recent advancements in bioremediation of dye: Current status and challenges. Bioresour. Technol. 2018, 253, 355-367. [CrossRef] [PubMed]

3. Cañizares, P.; Martínez, F.; Jiménez, C.; Lobato, J.; Rodrigo, M.A. Coagulation and electrocoagulation of wastes polluted with dyes. Environ. Sci. Technol. 2006, 40, 6418-6424. [CrossRef]

4. Xu, X.; Gao, B.; Yue, Q.; Zhong, Q.; Li, Q. Preparation of new types of anion exchange resins from agricultural by-products and their utilization in the removal of various toxic anions from solutions. Chem. Eng. J. 2011, 167, 104-111. [CrossRef]

5. Santhosh, C.; Velmurugan, V.; Jacob, G.; Jeong, S.K.; Grace, A.N.; Bhatnagar, A. Role of nanomaterials in water treatment applications: A review. Chem. Eng. J. 2016, 306, 1116-1137. [CrossRef]

6. Saber-Samandari, S.; Joneidi-Yekta, H.; Mohseni, M. Adsorption of anionic and cationic dyes from aqueous solution using gelatin-based magnetic nanocomposite beads comprising carboxylic acid functionalized carbon nanotube. Chem. Eng. J. 2017, 308, 1133-1144. [CrossRef]

7. Santos, S.C.R.; Boaventura, R.A.R. Treatment of a simulated textile wastewater in a sequencing batch reactor: (SBR) with addition of a low-cost adsorbent. J. Hazard. Mater. 2015, 291, 74-82. [CrossRef]

8. Holkar, C.R.; Jadhav, A.J.; Pinjari, D.V.; Mahamuni, N.M.; Pandit, A.B. A critical review on textile wastewater treatments: Possible approaches. J. Environ. Manag. 2016, 182, 351-366. [CrossRef]

9. Qin, L.; Zhang, G.; Meng, Q.; Zhang, H.; Xu, L.; Lv, B. Enhanced MBR by internal micro-electrolysis for degradation of anthraquinone dye wastewater. Chem. Eng. J. 2012, 210, 575-584. [CrossRef]

10. Du, X.; Shi, Y.; Jegatheesan, V.; Haq, I.U. A Review on the Mechanism, Impacts and Control Methods of Membrane Fouling in MBR System. Membranes 2020, 10, 24. [CrossRef]

11. Zhang, G.; Qin, L.; Meng, Q.; Fan, Z.; Wu, D. Aerobic SMBR/reverse osmosis system enhanced by Fenton oxidation for advanced treatment of old municipal landfill leachate. Bioresour. Technol. 2013, 142, 261-268. [CrossRef]

12. Zieli'nska, M.; Bernat, K.; Mikucka, W. Membrane Bioreactor Technology: The Effect of Membrane Filtration on Biogas Potential of the Excess Sludge. Membranes 2020, 10, 397. [CrossRef]

13. Supaka, N.; Juntongjin, K.; Damronglerd, S.; Delia, M.; Strehaiano, P. Microbial decolorization of reactive azo dyes in a sequential anaerobic-aerobic system. Chem. Eng. J. 2004, 99, 169-176. [CrossRef]

14. Libra, J.A.; Borchert, M.; Vigelahn, L.; Storm, T. Two stage biological treatment of a diazo reactive textile dye and the fate of the dye metabolites. Chemosphere 2004, 56, 167-180. [CrossRef] [PubMed]

15. Tian, Y.; Chen, L.; Zhang, S.; Cao, C.; Zhang, S. Correlating membrane fouling with sludge characteristics in membrane bioreactors: An especial interest in EPS and sludge morphology analysis. Bioresour. Technol. 2011, 102, 8820-8827. [CrossRef] [PubMed]

16. Meng, F.; Zhang, S.; Oh, Y.; Zhou, Z.; Shin, H.; Chae, S.R. Fouling in membrane bioreactors: An updated review. Water Res. 2017, 114, 151-180. [CrossRef]

17. Gu, Y.L.; Huang, J.H.; Zeng, G.M.; Shi, Y.H.; Hu, Y.; Tang, B.; Zhou, J.X.; Xu, W.H.; Shi, L.X. Quorum quenching activity of indigenous quorum quenching bacteria and its potential application in mitigation of membrane biofouling. J. Chem. Technol. Biotechnol. 2018, 93, 1394-1400. [CrossRef]

18. Pradhan, M.; Vigneswaran, S.; Kandasamy, J. Assessment of fouling behavior in submerged microfiltration system coupled with flocculation. J. Ind. Eng. Chem. 2015, 21, 254-260. [CrossRef]

19. Qin, L.; Liu, Q.; Meng, Q.; Fan, Z.; He, J.; Liu, T.; Shen, C.; Zhang, G. Anoxic oscillating MBR for photosynthetic bacteria harvesting and high salinity wastewater treatment. Bioresour. Technol. 2017, 22, 69-77. [CrossRef] [PubMed]

20. Chitapornpan, S.; Chiemchaisri, C.; Chiemchaisri, W.; Honda, R.; Yamamoto, K. Organic carbon recovery and photosynthetic bacteria population in an anaerobic membrane photo-bioreactor treating food processing wastewater. Bioresour. Technol. 2013, 141, 65-74. [CrossRef] [PubMed]

21. Kuo, F.; Chien, Y.H.; Chen, C. Effects of light sources on growth and carotenoid content of photosynthetic bacteria Rhodopseudomonas palustris. Bioresour. Technol. 2012, 113, 315-322. [CrossRef]

22. Munoz, R.; Guieysse, B. Algal-bacterial processes for the treatment of hazardous contaminants: A review. Water Res. 2006, 40, 2799-2815. [CrossRef]

23. Qin, L.; Fan, Z.; Xu, L.; Zhang, G.; Wang, G.; Wu, D.; Long, X.; Meng, Q. A submerged membrane bioreactor with pendulum type oscillation: (PTO) for oily wastewater treatment: Membrane permeability and fouling control. Bioresour. Technol. 2015, 183, 33-41. [CrossRef]

24. Adessi, A.; Philippis, R.D. Photobioreactor design and illumination systems for $\mathrm{H}_{2}$ production with anoxygenic photosynthetic bacteria: A review. Int. J. Hydrog. Energy 2014, 25, 3127-3141. [CrossRef]

25. Castillo, I.; Hernandez, P.; Lafuente, A.; Rodriguez-Llorente, I.D.; Caviedes, M.A.; Pajuelo, E. Self-bioremediation of corkprocessing wastewaters by (chloro)phenol-degrading bacteria immobilized onto residual cork particles. Water Res. 2012, 46, 1723-1734. [CrossRef]

26. Ng, K.K.; Shi, X.; Ng, H.Y. Evaluation of system performance and microbial communities of a bioaugmented anaerobic mem brane bioreactor treating pharmaceutical wastewater. Water Res. 2015, 81, 311-324. [CrossRef] 
27. Bashan, L.E.; Bashan, Y. Immobilized microalgae for removing pollutants: Review of practical aspects. Bioresour. Technol. 2010, 101, 1611-1627. [CrossRef] [PubMed]

28. Yeon, K.M.; Lee, C.H.; Kim, J. Magnetic enzyme carrier for effective biofouling control in the membrane bioreactor based on enzymatic quorum quenching. Environ. Sci. Technol. 2009, 43, 7403-7409. [CrossRef] [PubMed]

29. Smidsrod, O.; Skjak-Braek, G. Alginate as immobilization matrix for cells. Trends Biotechnol. 1990, 8, 71-78. [CrossRef]

30. Zhang, J.; Wang, L.; Yao, L.; Wang, Z.; Zhang, G. Novel polysulfone hybrid ultrafiltration membrane prepared with TiO ${ }_{2}$-g-HEMA and its antifouling characteristics. J. Membr. Sci. 2013, 436, 163-173. [CrossRef]

31. Hu, M.; Zheng, S.X.; Mi, B.X. Organic fouling of graphene oxide membranes and its implications for membrane fouling control in engineered osmosis. Environ. Sci. Technol. 2016, 50, 685-693. [CrossRef] [PubMed]

32. Zhao, C.; Lv, J.; Xu, X.; Zhang, G.; Yang, Y.; Yang, F. Highly antifouling and antibacterial performance of poly (vinylidene fluoride) ultrafiltration membranes blending with copper oxide and graphene oxide nanofillers for effective wastewater treatment. $J$. Colloid Interf. Sci. 2017, 505, 341-351. [CrossRef] [PubMed]

33. Zhao, C.; Xu, X.; Chen, J.; Wang, G.; Yang, F. Highly effective antifouling performance of PVDF/graphene oxide composite membrane in membrane bioreactor (MBR) system. Desalination 2014, 340, 59-66. [CrossRef]

34. Zhu, Y.; James, D.K.; Tour, J.M. New routes to graphene, graphene oxide and their related applications. Adv. Mater. 2012, 24, 4924-4955. [CrossRef]

35. Kim, S.R.; Lee, K.B.; Kim, J.E.; Won, Y.J.; Yeon, K.M.; Lee, C.H.D.; Lim, J. Macroencapsulation of quorum quenching bacteria by pol ymeric membrane layer and its application to MBR for biofouling control. J. Membr. Sci. 2015, 473, 109. [CrossRef]

36. APHA. Standard Methods for the Examination of Water and Wastewater, 20th ed.; American Public Health Association: Washington, DC, USA, 1998.

37. Zhang, G.; Zhou, M.; Xu, Z.; Jiang, C.; Shen, C.; Meng, Q. Guanidyl-functionalized graphene/polysulfone mixed matrix ultrafil tration membrane with superior permselective, antifouling and antibacterial properties for water treatment. J. Colloid Interf. Sci. 2019, 540, 295-305. [CrossRef] [PubMed]

38. Miao, W.; Li, Z.K.; Yan, X.; Guo, Y.J.; Lang, W.Z. Improved ultrafiltration performance and chlorine resistance of PVDF hollow fiber membranes via doping with sulfonated graphene oxide. Chem. Eng. J. 2017, 317, 901-912. [CrossRef]

39. Qin, L.; Zhang, Y.; Xu, Z.; Zhang, G. Advanced membrane bioreactors systems: New materials and hybrid process design. Bioresour. Technol. 2018, 269, 476-488. [CrossRef]

40. Qin, L.; Li, C.; Li, X.; Zhang, X.; Shen, C.; Meng, Q.; Shen, L.; Lu, Y.; Zhang, G. Confined encapsulation of living cells in self-assembly fiber macrospheres with micro/nanoporous polymer shell for transformation of contaminants to green energy. $J$. Mater. Chem. A 2020, 8, 1929-1938. [CrossRef]

41. Qin, L.; Gao, M.; Zhang, M.; Feng, L.; Liu, Q.; Zhang, G. Application of encapsulated algae into MBR for high-ammonia nitrogen wastewater treatment and biofouling control. Water Res. 2020, 187, 116430. [CrossRef]

42. Meng, F.; Zhang, H.; Yang, F.; Liu, L. Characterization of cake layer in submerged membrane bioreactor. Environ. Sci. Technol. 2007, 41, 4065-4070. [CrossRef] [PubMed]

43. Chen, Y.; Teng, J.; Shen, L.; Yu, G.; Li, R.; Xu, Y.; Wang, F.; Liao, B.; Lin, H. Novel insights into membrane fouling caused by gel layer in a membrane bioreactor: Effects of hydrogen bonding. Bioresour. Technol. 2019, 276, 219-225. [CrossRef] [PubMed]

44. Lee, W.; Kang, S.; Shin, H. Sludge characteristics and their contribution to microfiltration in submerged membrane bioreactors. J. Membr. Sci. 2003, 216, 217-227. [CrossRef]

45. Yan, L.; Li, R.; Song, Y.; Jia, Y.; Li, Z.; Song, L.; Zhang, H. Characterization of the Fouling Layer on the Membrane Surface in a Membrane Bioreactor: Evolution of the Foulants' Composition and Aggregation Ability. Membranes 2019, 9, 85. [CrossRef] [PubMed]

46. Johir, M.A.H.; Vigneswaran, S.; Sathasivan, A.; Kandasamy, J.; Chang, C.Y. Effect of organic loading rate on organic matter and foulant characteristics in membrane bioreactor. Bioresour. Technol. 2012, 113, 154-160. [CrossRef] [PubMed]

47. Qin, L.; Zhang, G.; Meng, Q.; Zhang, H.; Xu, L.; Lv, B. Enhanced submerged membrane bioreactor combined with biosurfactant rhamnolipids: Performance for frying oil degradation and membrane fouling reduction. Bioresour. Technol. 2012, 126, 314-320. [CrossRef]

48. Wang, G.; Fan, Z.; Wu, D.; Qin, L.; Zhang, G.; Gao, C.; Meng, Q. Anoxic/aerobic granular active carbon assisted MBR integrated with nanofiltration and reverse osmosis for advanced treatment of municipal landfill leachate. Desalination 2014, 349, 136-144. [CrossRef]

49. Shen, L.; Lei, Q.; Chen, J.; Hong, H.; He, Y.; Lin, H. Membrane fouling in a submerged membrane bioreactor: Impacts of floc size. Chem. Eng. J. 2015, 269, 328-334. [CrossRef]

50. Satyawali, Y.; Balakrishnan, M. Effect of PAC addition on sludge properties in an MBR treating high strength wastewater. Water Res. 2009, 43, 1577-1588. [CrossRef]

51. Wilen, B.M.; Jin, B.; Lant, P. The influence of key constituents in activated sludge on surface and flocculating properties. Water Res. 2003, 37, 2127-2139. [CrossRef]

52. Thompson, G.; Forster, C.F. Bulking in activated sludge plants treating paper mill wastewaters. Water Res. 2003, 37, $2636-2644$. [CrossRef] 